\title{
INDIGENOUS FOODWAYS OF THE GALO: A CHALLENGE TO ARCHAEOLOGY
}

\author{
Dr. Bina Gandhi Deori \\ Department of Ancient Indian History, Culture and Archaeology \\ Visva-Bharati, Santiniketan, West Bengal-731235, INDIA \\ Email: bina.gandhi@visva-bharati.ac.in
}

\begin{abstract}
The Galo are one among many tribes inhabiting the mountainous terrain of Arunachal Pradesh, located in the foothills of the Himalayas in Northeast India. The traditional subsistence practice of the Galo includes swidden cultivation popularly known as jhum in Northeast of India, animal husbandry and gathering. This paper discusses in detail their indigenous foodways and also explores the challenges regarding the archaeology of the food in the region.
\end{abstract}

Keywords: Arunachal Pradesh, Galo, indigenous, foodways

\section{INTRODUCTION}

Foodways have been critical to our understanding of the subsistence pattern of ancient societies though it remained unaddressed in academia for an extended period of time. However, in recent years, the significance of food and feasting has become extensively studied by both archaeologists and anthropologists, which resulted in a substantial amount of research exploring the importance, challenges and approaches towards foodways. Food tells us much about a people and their culture. The analysis of botanical remains from archaeological excavations can add a great deal of information regarding the reconstruction of the past lifeways of a society.

Delwen Samuel's (1996) article-“Approaches to the Archaeology of Food"- stresses on the importance of food, its significant role in the culture, challenges for the archaeology of food, and methods to overcome these challenges. He adds that the insight available from the careful choice of ethnographic analogues and accurate experimental replication should also not be overlooked (20:1996).

This current paper explores indigenous foodways and the challenges to the archaeology of food. It mainly draws upon ethnographic examples from the Galo tribe of Arunachal Pradesh in Northeast India. The paper also examines the factors that cause the difficulties in the preservation and recovery of food remains from the archaeological sites in Arunachal Pradesh, which result in a poor representation of the palaeo-botanical study of the region. Here the term 'foodways' has been used in its broadest sense. As an applied concept discussed in this article, it includes the first stage of collecting the ingredients, the use of different methods in order to produce a dish ready for consumption, as well as the final stage associated with food disposal. In a tribal society, food and drink serves more than just a biological need. Foods define gender relations and status differences. Through food and drink, social relations are built and further strengthened. Sharing of food is a common practice among tribal communities but with whom one should share, what to share and how much to share is an important element in the sharing processes which requires a judicious consideration.

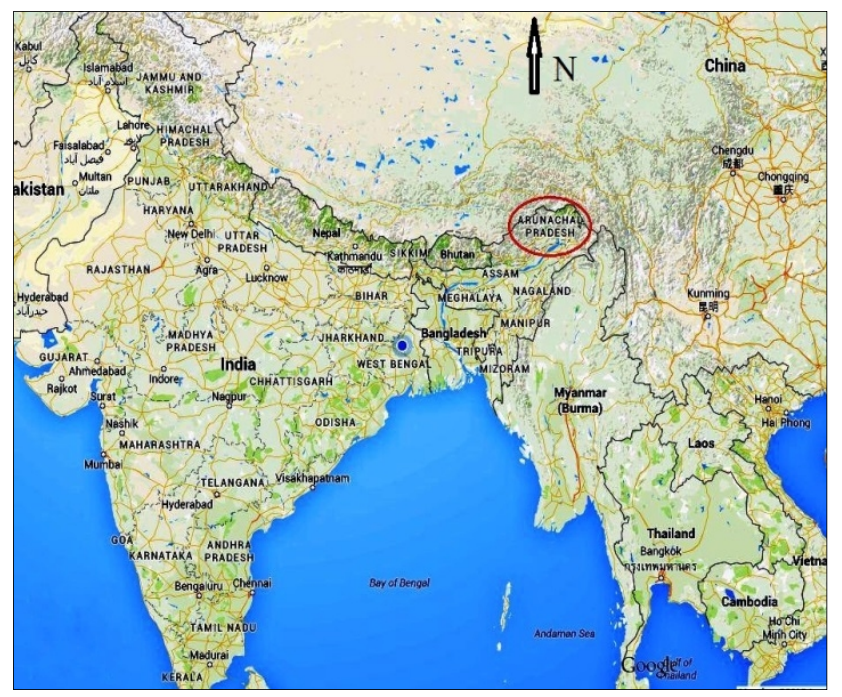

Figure 1: Arunachal Pradesh, North-East India

Arunachal Pradesh is the Northeasternmost state of India, laying in the foothills of the Himalayas. The state is prominently marked by mountainous terrain and undulating hills. Due to its difficult mountainous terrain, some parts of the region are still not easily accessible. It shares international boundaries with Bhutan to the west, Tibetan China to the north-west, Myanmar to the east and mainland China in the north (Fig 1.1). It also shares the same ecological zone with Southeast Asia. In many ways the cultures of Northeast India are akin to that of SE Asia. Many tribes of the Northeast region belong to the TibetoBurmese language group. Tribes such as the Khamti, Monpa, Lushai are spread over a large geographical re- 
gion in India, China, Burma and Thailand. According to Worman (1949), the Neolithic tradition of East Asia had made its way into India through the Northeast of India. Archaeologists working in the region have identified the pebble axes, choppers and pounders found in the Northeast as a Hoabinhian tool which is suggestive of a link with Southeastern Asia (Medhi 1993).

Realizing the potentiality of the area, an intensified archaeological research programme in NE India was considered important. Resolutions were made during the Indo-Pacific Prehistoric Congress in 1978 at Pune, India for gaining knowledge on early plant domestication in this area. However, no adequate efforts have been undertaken till date to identify the plants domesticated and cultivated first in this region (Jamir 2013).

Small scale excavations were conducted within the region but no direct evidence for domestication of animals and plants have been found so far. Recent excavations at six sites in Nagaland (New Phor, Chungliyimti, Khusomi, Khezhakeno, Movolomi and Phor), has provided the first direct archaeo-botanical evidence from this region. The recovered plant remains from these sites include Oryza sp. (rice), Triticum cf. aestivum L. (wheat), Paspalum sp. (kodon-millet), Setaria sp. (foxtail millet), Echinochloa sp. (wild millet), M. uniflorum (Lam.) Verdcourt (horsegram), L. sativus L. (grass pea), Gossypium arboreum/herbaceum L. (cotton), Bombax sp. (silkcotton), Coix sp. (Job's tears), E. officinalis Gaertn. (anwala), Zanthoxyllum sp. (tumburu) etc. This significant research work has opened up much more scope for future archaeological research programs in Northeast India.

Archaeological study is still in its nascent stage in Arunachal Pradesh. There is currently only one excavated Neolithic site, at Parsi-Parlo in the Lower Subansiri district. This was excavated in the year $1982-83$ by A.A Ashraf, the former Assistant Director of Research (Archaeology), under the Directorate of Research, Government of Arunachal Pradesh. No palaeo-botanical remains were recovered from this site but on the basis of ethnoarchaeological field-work conducted by the excavator in and around the village, it was found that the Nishyi tribe who inhabits the region had maintained rice as their staple diet. They also depended heavily on the gathering of wild plants, hunting of small and large animals, and fishing for their daily subsistence apart from agriculture.

According to the current state of Arunachal prehistory, hunting and fishing equipment are inconspicuous at present. Similarly, there is no site to represent the existence of a gathering economy because of poor preservation. As such, we cannot tell anything definitely about the food habits, especially as to which animals were eaten. It is also much more difficult to tell what plants were consumed by the prehistoric people. Perhaps, the devices that they have used for acquiring food were of non-metallic origin, made out of perishable materials which do not permit any records in the soil of this tropical country (Ashraf 1990:111).

The Galo is one of the most prominent tribes of Arunachal Pradesh. They speak Galo dialect which is a branch of the Tibeto-Burmese language group. As per the 2011 census, the Galo population was estimated at 112, 272 members. The present paper is based upon the fieldwork conducted in the years of 2010-12 in the Galo villages located in the West Siang District of Arunachal Pradesh, namely Bam, Nyigam, Gori, Nyorak, Soi, Pagi and Dari. The landscape that the Galo occupy is abundant in rich fauna and flora. They practice an array of subsistence methods however, agriculture has remained their main mode of subsistence. They practice both jhum or swidden cultivation and wet or terrace cultivation for agriculture methods. Yet jhum is the traditional practice that is also quite popular among many indigenous tribes in South and Southeast Asia. Rice is mainly grown in the mountains along with maize, millet and vegetables like lettuce, pumpkins, cucumbers etc. (Fig.1.2).

Animal breeding is another important subsistence activity among the Galo. Pigs, cows, chickens, and Mithun (Bos frontalis) are the most preferred livestock. These animals and fowls, not only supplement their need for protein, they also play an important role as offerings in their traditional rituals. Pigs, cows and chickens are raised within the boundary of the house whereas Mithun, which is a semi-domesticated animal, are left in the forest as a roaming herd. In the context of the Galo, the study of the human-animal relationship can make an interesting study as the animals have a symbolic value in their religious belief system too.

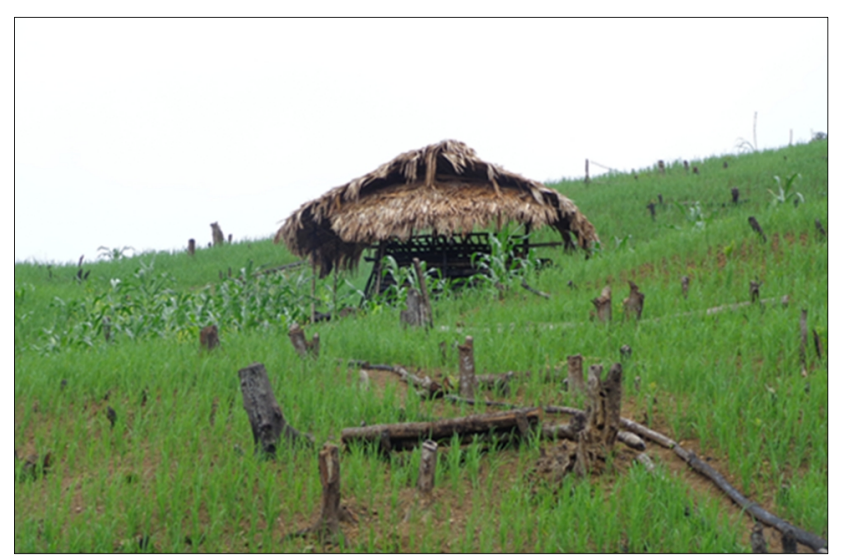

Figure 2: Swidden cultivation

Apart from agriculture and animal breeding, the Galo also practice a variety of food- gathering techniques. Most of their settlements are surrounded by forests with varieties of flora and fauna providing rich resources for subsistence. They gather wild foods, hunt game, trap birds from the forest, and fish from the streams. Years of living amidst of the forest, caused them to developed a pool of knowledge surrounding the properties of plant species that can be consumed as food and others that can be used as medicinal plants, likewise on the animal behavior, which suggests that they had a long tradition of utilizing resources from the forest. 
Gathering is an important method of food procurement among the Galo, especially for women. They are fully adept in identifying edible plants from the forest. On an average, they can easily identify more than 30 species of edible wild leaves, roots and mushrooms. Different kinds of wild potatoes, tubers, yams, mushrooms and leaves are collected usually on daily basis. In the villages, women regularly go to the forest to collect edible leaves and return back with a basket full of supplies to cook for the day. Some of the popular wild edible leaves are Pouzolzia viminea Urticaceae ('oik), Clerodendrom colebrookianum Walp. Verbenaceae ('oin- taap), Diplazium esculentum Retz (o-takaa) etc. During rituals and feasts, cooking is done on a large scale. Therefore, boys from the village volunteer to go to the forest and collect the wild edible plants. The Galo men are considered as expert hunters. With the changes in time, their mode of subsistence has also changed. Currently, people are largely employed in jobs or other livelihood earning activities. However, during the hunting season, the Galo men still go into the forests for hunting. In the villages, the narrations of the village elders about their hunting expeditions are still a famous topic for discussions during gatherings. The traditional Galo hunting techniques are mainly based upon their ability to understand animal behavior and to skillfully read the trails left by the animals.

The procured foods, both gathered and hunted, are cooked in the Galo traditional ways. These consist of mostly boiling, smoking, roasting, steaming and fermenting. Bamboo shoot is the chief ingredient which is used in all their traditional dishes. It can be consumed in a variety of ways by boiling, fermenting or drying. Boiling meat and fish along with tender bamboo shoots is the most common traditional cooking process of the Galo (Figure 3).
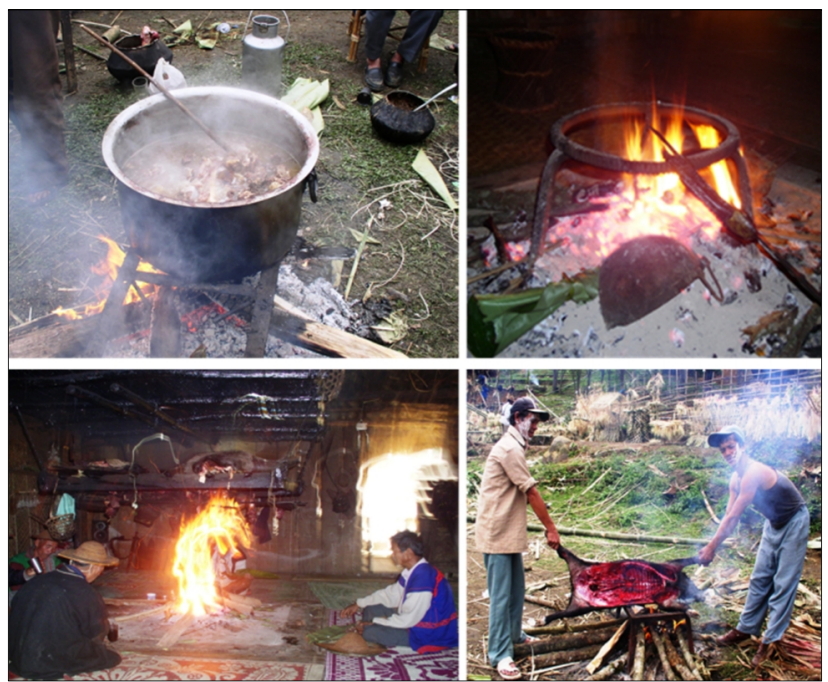

Figure 3: top left, boiling; bottom left, smoking; top right, steaming, and bottom right, roasting.

Meat and fish are usually consumed after being boiled or roasted. Certain parts of meat and fish are selected for steaming. For instance, the intestines of chicken are considered best to consume after being steamed. Steaming is usually done by stuffing the chopped pieces of meat along with the required condiments in a piece of leaf. Inside the fire place, a small space just large enough to hold the leaf bundle is made by removing the ash. The bundle containing the meat or fish is placed inside and covered by ash. Care is taken in order to put direct heat over it. Due to the heat of the fire, the bundle which is buried under the ash gets cooked. Smoking is a popular way to preserve meat and fish for a longer period of time. Meat and fish are smoked by leaving it on the overhanging shelf above the fire for few days. Constant heat from the wood fire makes the meat and fish smoked, which can be kept for longer periods of time thereby ensuring a sufficient stock of protein to keep them surviving throughout the cold winters.

During the fieldwork period, it was found that among the Galo, the use of pottery for cooking was not particularly popular. However, there are few instances of other tribes using pottery like the Apatani, Nyishi and the Nocte tribes of Arunachal Pradesh. Cooking in bamboo receptacles is still a tradition followed by the Galo during feasts and festivities. Rice is also cooked in bamboo tubes. Meat and fish along with wild edible plants are put inside the raw bamboo tubes. The bamboo tube is then covered and placed over the fire and from time to time the sides are turned to avoid burning of the food (Figure4).
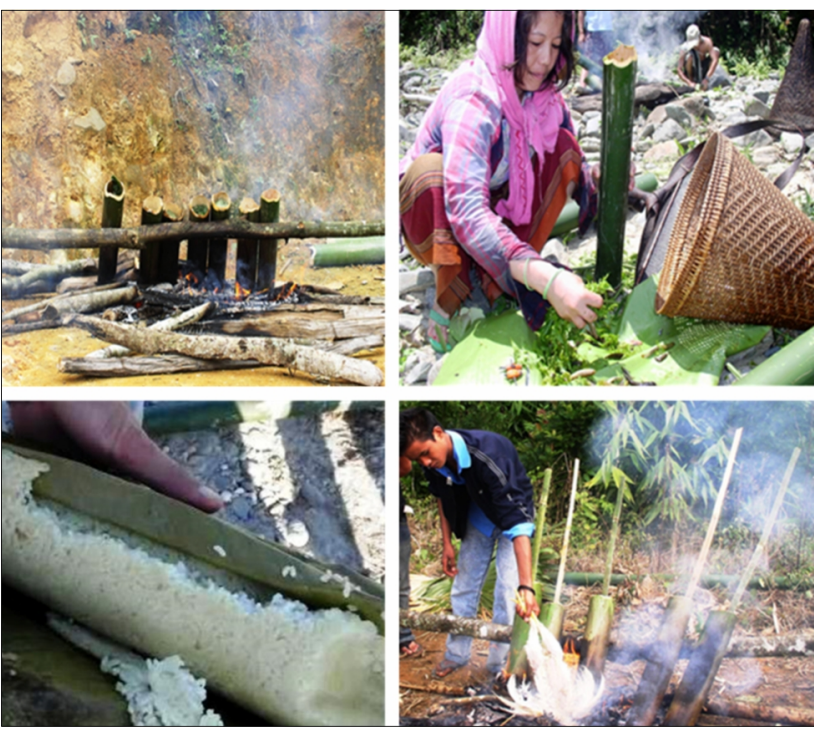

Figure 4: Cooking in bamboo.

Bamboo is abundantly available in their vicinity. It seems more plausible that they found it much easier to make use of the bamboo for cooking purposes rather than finding the right kind of clay and make pottery out of it. As such, it is a more efficient process considering the availability of bamboo as a resource.

Cooking on daily basis is done by the women but during feasts and festivities, cleaning and cooking of the meat is done by the men. Every Galo household has 2-3 hearths. Each heart has its own significance and the type 
of food to be cooked relates to that. For everyday cooking, the main hearth located in the center of the house is used. It is around this hearth that the main activities of the house take place. Guests are invited to sit near to the main hearth. The secondary hearth normally remains unused except for rare occasions like burning rice husk (used in making indigenous brew) and cooking for child bearing women. After the immediate birth of baby, the mother is not allowed to share in the same food that is cooked for the whole family as it is believed to pollute the main hearth which is considered sacred. Therefore, during those days of taboo, the mother's food is cooked in the secondary hearth. The third hearth which is located in the outer part of the house is used only during rituals and feasts when the need of an extra hearth is felt (Fig.1.5). Eating food covered in a leaf is a traditional practice of the Galo. During feasts, food is wrapped in leaves and distributed. Primarily, the leaf of Phrynium placentarium is used. For drinking purpose either bamboo tubes or mature gourds are used as containers (Figure 6).

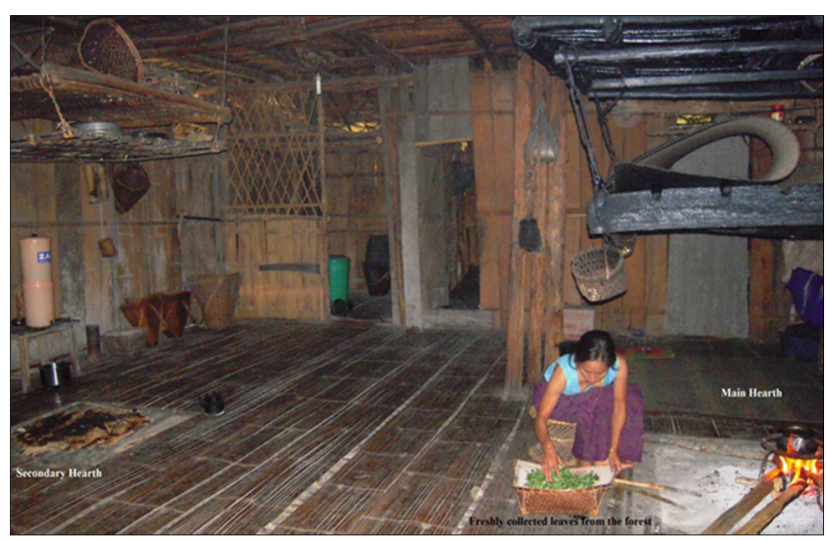

Figure 5: A Galo house with two hearths.

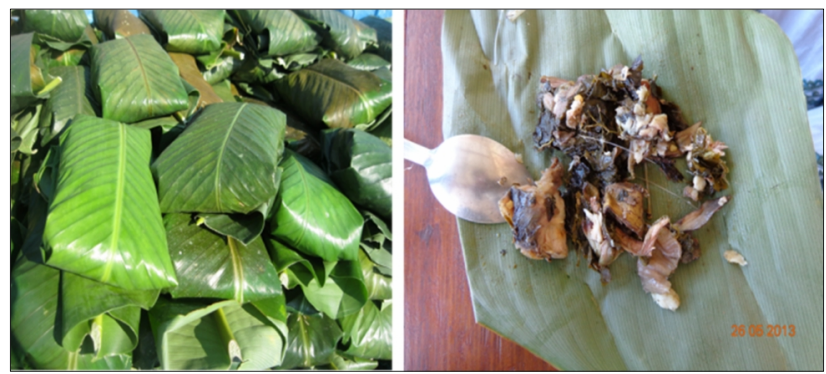

Figure 6: Leaves used for eating, serving and wrapping.

Regarding the food refuse, there are very limited chances of its recovery because the leftover food is given to the domesticated pigs. Due to the excessive humidity in the region, any faunal remains tend to get damaged. The ethnographic study of the Galo shows that they practice various modes of subsistence. However, the majority of them are done simply with bare hands or using very basic tools made of perishable materials thus leaving no records. The methods employed by the present tribe for hunt- ing and fishing with simple tools and devices suggest use of similar methods and approaches by the prehistoric people. Their vast knowledge of animal behavior as well as their skill in identifying the edible plants has accumulated over thousands of years and serves to be their most effective and important "tool" in hunting and gathering.

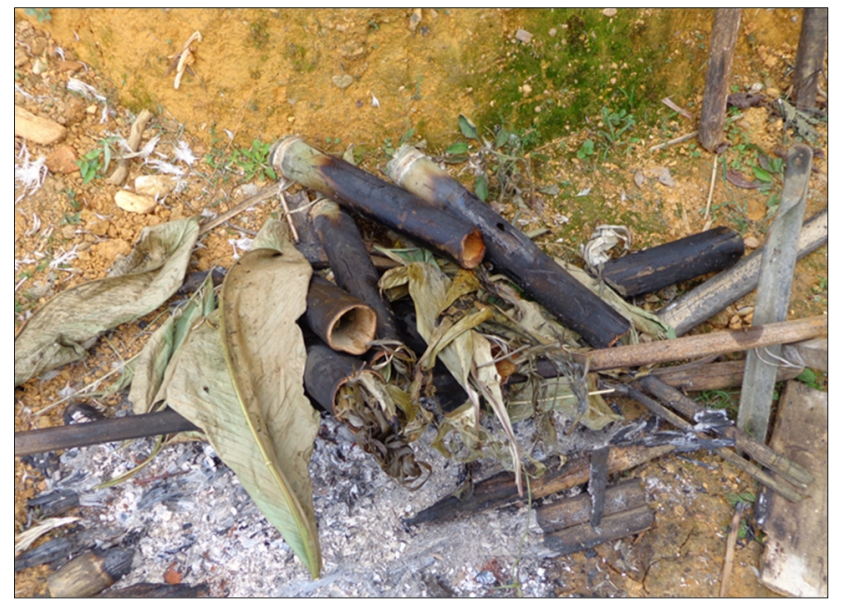

Figure 7: Bamboo tubes after use.

It is equally difficult after a considerable period of time to find the traces of the animal trails or the pitfalls which were previously used. Moreover, Galo hunting tools are mostly bows, arrows, traps and snares made of bamboo and wood that are perishable in nature and thereby leave no archaeological remains. In many cases, the bamboo tubes which were used for cooking are burnt into the fire after its purpose is over (Fig.1.7). Heavy rainfall and the acidic nature of the soil prove detrimental to the preservation of any archaeological remains and cultural material in their proper context. Thus, the indigenous foodways of the Galo pose a great challenge to the practice of archaeology with scanty and fragmentary remains. To reconstruct subsistence pattern of the Galos purely upon an archaeological approach would not be of much help without ethnographic observations. Thus, in the case of the Galo, ethnographic data helps us to get an insight to understand how prehistoric people survived.

The study of the traditional foodways of the indigenous communities of the Northeast in conjunction with ethnographic data is a crucial research area that needs to be explored to a greater degree in the future, in order to generate more archaeological evidence that can help to reconstruct the archaeological history of the region and its peoples.

\section{BIBLIOGRAPHY}

Aschmann, Homer. 1952. A Primitive Food Preparation Technique in Baja California. Southwestern Journal of Anthropology 8 (1): 36-39.

Ashraf, A.A. 1990. Prehistoric Arunachal (A report on archaeological exploration and excavation at Kamla Valley with reference to Parsi-Parlo of Lower Sunbansiri district, 
Arunachal Pradesh). Itanagar. Directorate of Research, Government of Arunachal Pradesh.

Capparelli. A., Valamoti, M. S. \& Wollstonecroft, M. M . 2011. After the harvest: investigating the role of food processing in past human societies. Archaeological and Anthropological Science 3: 1-5.

Delwen, Samuel. Approaches to the archaeology of food as a part of pioneering series of Seminars on Archaeology and Food held at the Institute of Archaeology, University College London, early in 1996. (http://ancientgrains.org/samuel1996food.pdf)

Deori, B. G. 2013. Ethnoarchaeological Study of the Adi-Galo tribe, Arunachal Pradesh. Unpublished Ph. D thesis, Department of Archaeology, Post Graduate and Research Institute, Yerawada, Pune.

Detwiler, K. R and VanDerwarker, A. M. 2002. Gendered practice in Cherokee Foodways: A spatial analysis of plant remains from the Coweeta Creek site. Southeastern Archaeology 21 (1): 21-28.

Du, B. C. M and Mintz, S.W. 2002. The Anthropology of Food and Eating. Annual Review of Anthropology. 31: 99-119.

Ebeling, Jennie R. and Yorke M. Rown. 2004. The Archaeology of the Daily Grind: Ground Stone Tools and Food Production in the Southern Levant. Near Eastern Archaeology, 67 (2): 108-117.

Gumerman IV, George. 1997. Food and Complex Societies. Journal of Archaeological Method and Theory 4 (2): 105139.

Hann, John H.1986. The Use and Processing of Plants by Indians of Spanish Florida. Southeastern Archaeology 5 (2): 91-102.

Jamir, Tiatoshi, Pokharia, A. K., Tetso, David and Venuh, Zokho. 2013. Late first millennium BC to second millennium AD agriculture in Nagaland: a reconstruction based on archaeobotanical evidence and radiocarbon dates, Current Science 104 (10): 1341-1353.

Medhi, D.K. (Ed.). 1993. Geology of North-East India. Man and Environment of North-East India. Omsons, Guwahati

Nagaoka, Lisa. 2002. Explaining Subsistence Change in Southern New Zealand Using Foraging Theory Models. World Archaeology 34 (1): 84-102.

Twiss, Katheryn. 2012. The Archaeology of Food and Social Diversity. Journal of Archaeological Research. 20: 357395

Worman, E. C. 1949. "The Neolithic problem in the Prehistory of India". Journal of the Washington Academy of Sciences, 39 (6), pp. 181-201.

Zulauf, M R. 2013. Indigenous Cuisine: An Archaeological and Linguisic Study of Colonial Zapotec Foodways on the Isthmus of Tehuantepec. Graduate Master Thesis, University of Massachusetts, Boston. 